\title{
The influence of residual salivary fluoride from dentifrice on enamel erosion: an in situ study
}

\author{
Ana Carolina Magalhães ${ }^{(a)}$ \\ Daniela Rios ${ }^{(\mathrm{c})}$ \\ Cleide Cristina Rodrigues \\ Martinhon $^{(b)}$ \\ Alberto Carlos Botazzo Delbem ${ }^{(b)}$ \\ Marília Afonso Rabelo Buzalaf(c) \\ Maria Aparecida de Andrade \\ Moreira Machado(d) \\ (a) MSc; (b)PhDs - Department of Child and \\ Social Dentistry, School of Dentistry of \\ Araçatuba, São Paulo State University. \\ (c) PhDs, Department of Biological Sciences \\ (d) PhD, Department of Pediatric and \\ Preventive Dentistry and Orthodontics \\ - School of Dentistry of Bauru, University of \\ São Paulo.
}

Corresponding author:

Marília Afonso Rabelo Buzalaf

Alameda Octávio Pinheiro Brisolla, 9-75

Bauru - SP - Brazil

CEP: 17012-901

E-mail:mbuzalaf@fob.usp.br

Received for publication on Nov 23, 2006

Accepted for publication on May 08, 2007

\begin{abstract}
The objective of this study was to assess the salivary residual effect of fluoride dentifrice on human enamel subjected to an erosive challenge. This crossover in situ study was performed in two phases (A and B), involving ten volunteers. In each phase, they wore acrylic palatal appliances, each containing 3 human enamel blocks, during 7 days. The blocks were subjected to erosion by immersion of the appliances in a cola drink for 5 minutes, 4 times a day. Dentifrice was used to brush the volunteers' teeth, 4 times a day, during 1 minute, before the appliance was replaced into the mouth. In phases $A$ and $B$ the dentifrices used had the same formulation, except for the absence (PD) or presence (FD) of fluoride, respectively. Enamel alterations were determined using profilometry, microhardness (\%SMHC), acid- and alkali-soluble $\mathrm{F}$ analysis. The data were tested using ANOVA $(\mathrm{p}<0.05)$. The concentrations (mean $\mathrm{r} \mathrm{SD})$ of alkali- and acid-soluble $\mathrm{F}\left(\mathrm{PgF} / \mathrm{cm}^{2}\right)$ were, respectively, PD: $1.27^{\mathrm{a}} \mathrm{r} 0.70 / 2.24^{\mathrm{A}} \mathrm{r} 0.36$ and FD: $1.49^{\mathrm{a}} \mathrm{r} 0.44 / 2.24^{\mathrm{A}} \mathrm{r} 0.67$ $(\mathrm{p}>0.05)$. The mean wear values ( $\mathrm{r}$ SD, $\mathrm{Pm})$ were PD: $3.63^{\mathrm{a}} \mathrm{r} 1.54$ and FD: $3.54^{\mathrm{a}} \mathrm{r} 0.90(\mathrm{p}>0.05)$. The mean \%SMHC values ( $\mathrm{SD}$ ) were PD: 89.63 $\mathrm{a} 4.73$ and FD: 87.28 $\mathrm{r} 4.01$ ( $\mathrm{p}>0.05$ ). Thus, we concluded that the residual fluoride from the fluoride-containing dentifrice did not protect enamel against erosion.
\end{abstract}

Descriptors: Tooth erosion; Dental enamel; Fluorine. 


\section{Introduction}

While the incidence of the major dental disease, caries, has declined in the developed countries, ${ }^{1}$ conditions such as dental erosion are becoming increasingly important. ${ }^{2}$ Dental erosion is defined as the loss of tooth substance by chemical processes not involving bacteria ${ }^{2}$ caused by a variety of extrinsic and intrinsic factors. ${ }^{3,4}$ In modern societies the extrinsic factor is becoming more important, due to the increased consumption of acid drinks as soft drinks, sport drinks, fruit juices and fruit teas. ${ }^{5}$

For erosion prevention, many strategies have been used, like the topical application of fluoride. Although the preventive action of fluoride on dental caries is well known, ${ }^{6,7}$ its role in erosion is still controversial. ${ }^{8,9}$ Topical fluoride applications in the form of oral rinses, gels or varnishes appear to be effective for reducing effects related to erosive attacks. In particular, high-concentrated fluoride applications have been demonstrated, in some cases, to increase abrasion resistance and decrease the development of erosion in enamel. ${ }^{9-13}$

In contrast, other studies have shown in vitro that fluoride dentifrices provided little protection against erosion. ${ }^{14,15}$ However, the effect of residual salivary fluoride from dentifrices used in situ and its possible mechanism of action with or without the formation of calcium fluoride in an erosive challenge still needs clarification.

Taking these aspects into account, the purpose of this study was to assess the effect of residual fluoride from dentifrice, present in saliva, on enamel subjected to erosion in situ.

\section{Material and Methods \\ Experimental design}

This study was approved by the Research and Ethics Committee, School of Dentistry of Bauru, University of São Paulo (Proc n ${ }^{\circ}$ 49/2003). The study had a crossover and double blind design, performed in two phases of 7 days, with washout of 10 days between the phases. The difference between the two phases was the dentifrice used for oral hygiene performed 4 times a day after an erosive attack. The dentifrices had the same formula- tions, except for the absence (PD) or presence (FD) of fluoride. Ten healthy adult volunteers with a mean age of 24 years (range 19-30 years), with a normal salivary flow rate, and residing in a fluoridated area $(0.70 \mathrm{mgF} / \mathrm{L})$ took part in this study. In each phase, they wore acrylic palatal appliances, which contained 3 human dental enamel blocks. The blocks were subjected to erosion by immersion in a cola drink. Before the appliance was returned into the mouth, the volunteers brushed their teeth using one of the dentifrices. Enamel alterations were determined using profilometry, microhardness assessment (\%SMHC), and acid- and alkali-soluble $\mathrm{F}$ analysis.

\section{Enamel blocks and palatal appliance preparation}

Enamel blocks $(4 \times 4 \times 3 \mathrm{~mm})$ were prepared from freshly extracted, impacted human third molars, which were sterilized by storage in $2 \%$ formaldehyde solution ( $\mathrm{pH}$ 7.0) for 30 days at room temperature. The enamel surface of the blocks was ground flat with water-cooled carborundum discs (320, 600 and 1,200 grades of $\mathrm{Al}_{2} \mathrm{O}_{3}$ papers; Buehler, Lake Bluff, IL, USA), and polished with felt paper wet by diamond spray (1 Pm; Buehler), resulting in the removal of about $100 \mathrm{Pm}$ in depth of the enamel, which was controlled with a micrometer. Surface microhardness was determined by five indentations in different regions of the blocks (Knoop diamond, 25 g, 5 s, HMV-2000; Shimadzu Corporation, Tokyo, Japan).

Sixty blocks with a mean surface microhardness around $350 \mathrm{r} 15 \mathrm{KHN}$ were randomly divided into two groups. In order to maintain reference surfaces for lesion depth determination, two layers of nail varnish were applied on half of the surface of each block. On the intraoral palatal appliances, 3 cavities of $5 \times 5 \times 3 \mathrm{~mm}$ were made and, into each of them, one block of enamel was fixed with wax.

\section{Treatments}

Ten days prior to the beginning of the experiment, and throughout the experimental phase, the volunteers brushed their teeth with Crest $^{\circledR}$ denti- $^{-}$ frice ( $\mathrm{pH}$ 6.8; silica as abrasive; Procter and Gam- 
ble, Mason, OH, USA), half of them with fluoride $(\mathrm{NaF} 1,098 \mathrm{ppm} \mathrm{F}-\mathrm{FD})$ and the other half without fluoride (PD), depending on the phase that they took part in. The volunteers were randomly allocated to treatments and those who used PD in the first phase (A) used FD in the second phase (B), and vice versa.

In the first 12 hours of the intraoral phase, the blocks were not subjected to any erosive attack to allow the formation of a salivary pellicle. On the following 7 days, an erosive challenge was made extraorally 4 times a day and at predetermined times $(8.00,12.00,16.00$ and $20.00 \mathrm{~h})$.

The volunteers were instructed to remove the appliance and immerse it in a cup containing $150 \mathrm{ml}$ of a freshly opened bottle of regular Coke ${ }^{\circledR}, \mathrm{pH} 2.5$ (Spal, Porto Real, RJ, Brazil) at room temperature, for 5 min. ${ }^{16}$ Before the appliance was replaced into the mouth, the volunteers performed their oral hygiene with a soft end-rounded toothbrush (Sorriso Infantil ${ }^{\circledR}$, Colgate-Palmolive, São Paulo, SP, Brazil) with a small portion of the dentifrice (approximately $0.3 \mathrm{~g}),{ }^{16,17}$ during 1 minute.

The volunteers received instructions to wear the appliances continuously, including at night, but to remove them during meals (3 times a day) or when drinking water. Volunteers were instructed not to use fluoride products. Plaque control on the blocks was achieved by dipping the appliance in a $0.2 \%$ chlorhexidine gluconate solution for 5 minutes at the end of each study day.

\section{Wear assessment}

At the end of each phase, the enamel blocks were removed from the appliances and the nail varnish over the surfaces was carefully cleaned with acetone-soaked cotton wool..$^{18}$ The blocks were dried and the enamel wear was determined in relation to the reference surface, by profilometry using a rugosimeter (T1000 Tester; Hommelwerke, VS-Schwenningen, Germany). Four readings were performed on each specimen through scanning from the reference to the exposed surface. The average wear depth of each group by volunteer (experimental unit) was computed using the 12 readings performed: three blocks versus four readings.

\section{Percentage of superficial microhardness change assessment (\%SMHC)}

After the wear assessment, enamel surface microhardness was measured as described earlier and an average per volunteer was obtained. Ten indentations on each specimen were made, five on the previously protected enamel surface $(\mathrm{SMH})$ and five on the experimental area $\left(\mathrm{SMH}_{1}\right)$. Using these measurements, the percentage change in surface microhardness (\%SMHC) was calculated, as:

$$
\% \mathrm{SMHC}=\left\{\left[\left(\mathrm{SMH}_{-} \mathrm{SMH} \mathrm{H}_{1}\right) / \mathrm{SMH}\right] \text { u } 100\right\} .
$$

\section{Determination of alkali-soluble $\mathbf{F}$ in enamel}

The concentration of alkali-soluble $\mathrm{F}$ was evaluated using the method described by Caslavska et al. ${ }^{19}$ (1975). A circular hole (2.0 mm diameter) was punched in adhesive tape, which was applied firmly to the center of the enamel block. The remaining surfaces of the block were painted with acid-resistant nail varnish so that only a $3.14 \mathrm{~mm}^{2}$ surface area was exposed. The block was then placed in a plastic test tube containing $0.50 \mathrm{ml}$ of $1 \mathrm{M} \mathrm{KCl}$ for $24 \mathrm{~h}$ under constant agitation. An equal volume of TISAB II (containing $\mathrm{HCl}$ ) was added. This solution was analyzed with the electrode, along with standards containing from 0.025 to $3.2 \mathrm{PgF} / \mathrm{mL}$. The data were expressed as $\mathrm{PgF} / \mathrm{mm}^{2}$.

\section{Determination of acid-soluble $F$ in enamel}

In the same circular area mentioned above, one layer of enamel was removed by immersion in $0.25 \mathrm{ml}$ of $0.5 \mathrm{M} \mathrm{HCl}$ for $15 \mathrm{~s}$ under agitation. An equal volume of TISAB II, pH 5.0, was added. Fluoride was determined as mentioned above. The thickness of the enamel layer removed during the acid biopsy was calculated from the inorganic phosphorus concentration, determined by the method of Fiske, Subarrow $^{20}$ (1925). A phosphorus content in enamel of $17.4 \%$ and enamel density of 3.0 were assumed ${ }^{21}$ to calculate, respectively, the amount of enamel removed and the depth of each enamel layer.

\section{Statistical analysis}

The assumptions of equality of variances and 
Table 1 - Analysis of the enamel blocks according to treatments (means $r$ SD, $n=10$ ).

\begin{tabular}{|c|c|c|c|c|}
\hline Groups* & $\begin{array}{c}\text { Alkali-soluble F } \\
\left(\mathrm{PgF} / \mathrm{cm}^{2}\right)\end{array}$ & $\begin{array}{c}\text { Acid-soluble F } \\
\left(\mathrm{PgF} / \mathrm{cm}^{2}\right)\end{array}$ & $\begin{array}{l}\text { Wear } \\
(\mathrm{Pm})\end{array}$ & $\mathrm{SMH} / \mathrm{SMH}_{1}(\% \mathrm{SMHC})$ \\
\hline PD & 1.27 r 0.70 & $2.24 \times 0.36$ & $3.63 \times 1.54$ & 357.60 r 14.38 / 37.14 r 24.58 (89.63 r 4.73) \\
\hline FD & 1.49 r 0.44 & 2.24 r 0.67 & $3.54 \mathrm{r} 0.90$ & 357.76 r 15.40 / 45.60 r 20.73 (87.28 r 4.01$)$ \\
\hline
\end{tabular}

* No significant differences were detected between the two groups for any of the variables tested $(p>0.05)$.

normal distribution of errors were checked for all the variables tested. Since the assumptions were satisfied, ANOVA was carried out for statistical comparisons and the significance limit was set at $5 \%$.

\section{Results}

Table 1 shows that there were no significant differences $(p>0.05)$ between the groups in respect to the presence of fluoride in enamel. Moreover, the use of FD did not significantly reduce the wear and the \%SMHC of eroded enamel in comparison to PD ( $\mathrm{p}>0.05)$.

\section{Discussion}

The results of this study demonstrated that exposure to a cola soft drink for 5 minutes, 4 times per day, induced softening and wear of tooth enamel. The erosive potential of the cola drink was in accordance with that of other studies. ${ }^{16,22}$ Therefore, it must be emphasized that an acidic drink can cause severe erosion, mainly when combined to frequent consumption or abnormal swallowing patterns, such as prolonged intraoral storage.

The residual fluoride from dentifrice, present in saliva, had no significant effect on \%SMHC (softening) and wear of eroded enamel by cola drinks in agreement with the studies of Lagerweij et al. ${ }^{14}$ (2006) and Ponduri et al. ${ }^{15}$ (2005). In the present study, the FD did not get in contact with eroded enamel surfaces because the palatal appliances were removed from the mouth during brushing with the fluoride dentifrice. This was done to avoid the contact of the toothbrush with the blocks, which could result in enamel block abrasion, thus influencing the results. Thus, the enamel blocks were not exposed to the highest fluoride concentrations as may occur with the subject's teeth. As a consequence, the formation of calcium fluoride-like material (alkalisoluble Fluoride) and fluorapatite (acid-soluble Fluo- ride) was not significantly different from that of the placebo dentifrice. Another factor that might have contributed for this result was the number of volunteers $(n=10)$, which may have been insufficient for detecting significant differences between groups.

Moreover, in accordance with other findings in the related literature, the increases in salivary $\mathrm{F}$ after using a fluoride dentifrice are usually very limited and of short duration, $9,23,24$ which could explain the small formation of fluoride in enamel found in the present study. It must be highlighted that the fluoride concentration in saliva was not evaluated during the experimental phase due to the difficulties in collecting the material accurately after each toothbrushing, since the volunteers executed the experiment at home.

In face of the disappointing findings regarding the effect of residual fluoride on dental erosion, other strategies are required, such as beverage modification, ${ }^{25,26}$ consumption of cheese ${ }^{27}$ or milk ${ }^{28}$ and salivary stimulation ${ }^{16}$ after the acid attack. However, the beneficial action of these alternative therapies should be better studied before they can be clinically recommended with reasonable assurance of their beneficial effect.

Recent studies have demonstrated that the use of higher concentrations of fluoride in the form of oral rinses, gels or varnishes before and after the consumption of acid drinks could decrease enamel loss. ${ }^{9-11,29}$ However, the influence of residual salivary fluoride from dentifrice on enamel erosion should be studied by dripping the dentifrice slurry on the enamel blocks in situ to confirm the present data.

\section{Conclusions}

Our in situ results confirm those of studies conducted in vitro, showing that residual salivary fluoride from dentifrice does not present a preventive 
effect against erosion. This finding is important for future experimental designs related to the effect of fluoride on erosive challenges in situ, because the volunteers can use fluoride-containing dentifrices without influencing the results.

\section{References}

1. Brown LJ, Wall TP, Lazar V. Trends in total caries experience: permanent and primary teeth. J Am Dent Assoc. 2000;131(2):223-31.

2. Imfeld T. Dental erosion. Definition, classification and links. Eur J Oral Sci. 1996;104(2):151-5.

3. Eccles JD. Tooth surface loss from abrasion, attrition and erosion. Dent Update. 1982;9(7):373-81.

4. Smith BG. Toothwear: aetiology and diagnosis. Dent Update. 1989;16(5):204-12.

5. Lussi A, Jaeggi T, Zero D. The role of diet in the aetiology of dental erosion. Caries Res. 2004;38(Suppl 1):34-44.

6. Ogaard B. Effects of fluoride on caries development and progression in vivo. J Dent Res. 1990;69 Spec No:813-9.

7. Ten Cate JM. Review on fluoride, with special emphasis on calcium fluoride mechanisms in caries prevention. Eur J Oral Sci. 1997;105(5):461-5.

8. Larsen MJ, Richards A. Fluoride is unable to reduce dental erosion from soft drinks. Caries Res. 2002;36(1):75-80.

9. Wiegand A, Attin T. Influence of fluoride on the prevention of erosive lesions - a review. Oral Health Prev Dent. 2003;1(4):245-53.

10. Buchalla W, Lagerwey M, Kohnke S, Becker K, Lennon AM, Attin T. Fluoride is able to reduce erosive and erosive/abrasive enamel loss under severe erosive conditions. Caries Res. 2004;38(4):291.

11. Ganss C, Klimek J, Brune V, Schurmann A. Effects of two fluoridation measures on erosion progression in enamel and dentine in situ. Caries Res. 2004;38(6):561-6.

12. Hughes JA, West NX, Addy M. The protective effect of fluoride treatments against enamel erosion in vitro. J Oral Rehabil. 2004;31(4):357-63.

13. Schluter N, Ganss C, Ort R, Schmidt R, Klimek J. Retention of fluoride and titanium on enamel under erosive conditions in vitro. Caries Res. 2004;38(6):392.

14. Lagerweij MD, Buchalla W, Kohnke S, Becker K, Lennon AM. Prevention of erosion and abrasion by a high fluoride concentration gel applied at high frequencies. Caries Res. 2006;40(2):148-53.

15. Ponduri S, Macdonald E, Addy M. A study in vitro of the combined effects of soft drinks and tooth brushing with fluoride toothpaste on the wear of dentine. Int J Dent Hyg. 2005; 3(1):7-12.

16. Rios D, Honório HM, Magalhães AC, Machado MAAM, Delbem ACB, Silva SMB et al. Effect of salivary stimulation on

\section{Acknowledgments}

We wish to thank the volunteers that took part in this study. This study was partially supported by the Coordination for the Improvement of Higher Education Personnel (CAPES).

erosion subjected or not to abrasion in human and bovine enamel: an in situlex vivo study. Caries Res. 2006;40(6):218-26.

17. Attin T, Zirkel C, Hellwig E. Brushing abrasion of eroded dentin after application of sodium fluoride solutions. Caries Res. 1998;32(5):344-50.

18. Attin T, Buchalla W, Gollner M, Hellwig E. Use of variable remineralization periods to improve the abrasion resistance of previously eroded enamel. Caries Res. 2000;34(1):48-52.

19. Caslavska V, Moreno EC, Brudevold F. Determination of the calcium fluoride formed from in vitro exposure of human enamel to fluoride solutions. Arch Oral Biol. 1975; 20(5-6):333-9.

20. Fiske CH, Subarrow Y. The colorimetric determination of phosphorus. J Biol Chem. 1925;66:375-400.

21. Lazzari EP. Dental biochemistry. $2^{\text {nd }}$ ed. London: Lea $\&$ Febiger; 1976.

22. Fushida CE, Cury JA. Estudo in situ do efeito da freqüência de ingestão de coca-cola na erosão do esmalte-dentina e reversão pela saliva. Rev Fac Odontol USP. 1999;13(2):127-34.

23. Issa AI, Toumba KJ. Oral fluoride retention in saliva following toothbrushing with child and adult dentifrices with and without water rinsing. Caries Res. 2004;38(1):15-9.

24. Zero DT, Raubertas RF, Fu J, Pedersen AM, Hayes AL, Featherstone JD. Fluoride concentrations in plaque, whole saliva, and ductal saliva after application of home-use topical fluorides. J Dent Res. 1992;71(11):1768-75.

25. Hughes JA, West NX, Parker DM, Newcombe RG, Addy M. Development and evaluation of a low erosive blackcurrant juice drink. 3. Final drink and concentrate, formulae comparisons in situ and overview of the concept. J Dent. 1999;27(5):345-50.

26. West NX, Hughes JA, Parker DM, Newcombe RG, Addy M. Development and evaluation of a low erosive blackcurrant juice drink. 2. Comparison with a conventional blackcurrant juice drink and orange juice. J Dent. 1999;27(5):341-4.

27. Lewinstein I, Ofek L, Gedalia I. Enamel rehardening by soft cheeses. Am J Dent. 1993;6(1):46-8.

28. Gedalia I, Dakuar A, Shapira L, Lewinstein I, Goultschin J, Rahamim E. Enamel softening with coca-cola and rehardening with milk or saliva. Am J Dent. 1991;4(3):120-2.

29. Lussi A, Jaeggi T, Megert B. Effect of various fluoride regimes on toothbrush abrasion of softened enamel in situ. Caries Res. 2004;38(6):393. 